\title{
Book review: S. Mirzaei and M. Schenk (eds) Abbilder der Folter
}

\author{
Mandelbaum, Vienna, 2010, 179 p, ISBN 978-3-85476-351-2
}

Torture for reasons of political or religious antagonism or in conditions of war is defined as a deliberate harm to physical and/or psychic human integrity. In this Germanlanguage book, Mirzaei and Schenk, together with other authors, describe the work over 15 years of Hemayat, a nonprofit organization in Vienna, with refugees traumatized by torture. Clinical and psychological post-torture syndromes are described. Psychological support methods are outlined. The physiopathological consequences of torture methods are detailed in medical and especially scintigraphic images. Consequences of blows, falls, forced hangings, vicious positions, subluxations, amputations or osteo-articular disruptions, perpetrated up to several years before imaging, are documented. Pathological bone consolidations, calcified posttraumatic haematomas, peri-articular calcifications and subluxations are described.

The committed writing by several authors with different professional specializations is interesting. The book describes the relevance of nuclear medicine methods in documenting the consequences of torture. Among other symptoms, tortured patients often complain of chronic pain. Medical proof via imaging of the physiopathological consequences of past torture is a first step towards psychological work-up. It is to be noted, however, that the legends of the illustrations are not always self-explanatory.

C. Als
"Society communications"

Publish items of general interest for the nuclear medicine community:

- Reports on Meetings

- National Society news

- Courses, Fellowships

- Other items of interest

Announcements of meetings or industry advertisements cannot be published in this section.

Mail your text to societynews@eanm.org icarrio@santpau.cat 